\title{
Does Plate Size Used in Food Service Affect Portion Perception?
}

\author{
Yemek Servisinde Kullanılan Tabakların Boyutu Porsiyon Algısını Etkiliyor \\ $\mathrm{mu}$ ? \\ Can Öner*I, Mehtap Özdemir ${ }^{2}$, Berrin Telatar ${ }^{3}$, Şahin Yeşilda $\breve{g}^{2}$
}

\begin{abstract}
Introduction: One of the environmental factor affect obesity is increased size of food portions. According to widespread belief people consume much more food with large plates The food portion perception could be changed with the size of plates. The aim of this study was to evaluate the effect of plate size on food portion perception. Methods: This experimental study includes 100 students with ages ranged 20-34 years. One portion of pasta was served with three different plates. And the portion of pasta was asked to determined for each plates from each participants separately. The data was analyzed by SPSS 17.0 and p value below 0.05 was considered as significant. Results: The rate of Delboeuf illusion in second plate was $\% 7$ and it reaches up to $23 \%$ in third plate. Nearly half of the participants (49\%) had Delboeuf illusion with first plate. The accuracy of portion evaluations of attendance does not show significant difference according to gender and body mass index. Conclusion: As a result, serving foods with small plates may reduce the amount of food and decrease the energy intake. Therefore, it could be used for a cost effective method for obesity fight.
\end{abstract}

Key words: Obesity, portion sizes, services, energy intake

ÖZET

Giriş: Obeziteye etki eden çevresel faktörlerden birisi de porsiyonların büyümesidir. Büyük tabaklarla yapılan yemek sunumlarında bireyler daha fazla besin tüketmektedir. Gıdanın değişik tabak boyutları ile sunulması durumunda, porsiyon algısı değişebilmektedir. Bu çalışmanın amacı, tabak boyutunun yiyecek porsiyonlarının görsel tahmini üzerine etkisini incelemektir. Yöntem: Deneysel tipteki bu çalışmanın evrenini, yaş aralıkları 20-34 arasında değişen 100 öğrenci oluşturdu. Pişirilmiş 1 porsiyon makarna, çalışmaya katılanlara, boyutları ve şekilleri farklı üç ayrı tabakta sunuldu. Tabaklardan birincisi küçük düz, ikincisi büyük düz, üçüncüsü ise orta boy çukur tabaktı. Her bir katılımcıdan, görsel açıdan tabaklardaki makarna porsiyonlarını tahmin etmeleri istendi (yarım, bir porsiyon, 1.5 porsiyon vs). Elde edilen veriler SPSS 17.0 programı kullanılarak analiz edildi. P değerleri, 0,05 altında olan değeler anlamlı olarak kabul edildi. Bulgular: Çalışmaya katılanların

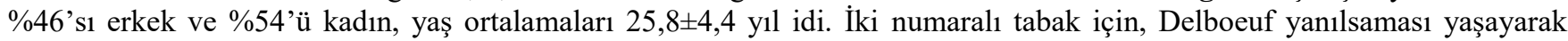
servis edilen makarnayı bir porsiyondan az bulanların oranı \%7 iken, 3 numaralı tabak için yanılsama yaşayanların oranı \%23'tü. En çok yanılsama bir numaralı tabakta yaşandı (\%49). Servis edilen makarnanın porsiyonunu doğru tahmin etme açısından, cinsiyet ve beden kitle indeksi açısından her üç tabak için anlamlı bir farklılık bulunamadı (p>0,05). Sonuç: Yemeklerin daha küçük kaplarda servis edilmesinin, algılanan porsiyon miktarını değiştirerek kişilerin enerji alımlarını azaltacağından, obeziteyle mücadele açısından etkin bir yöntem olarak kullanılabileceği düşünüldü.

Anahtar kelimeler: Obezite, porsiyon büyüklüğü, servis, enerji alımı

Received / Geliş tarihi: 15.08.2016, Accepted / Kabul tarihi: 08.10.2016

${ }^{1}$ Dr.Lütfi Kırdar Eğitim ve Araştırma Hastanesi Aile Hekimliği Kliniği

${ }^{2}$ İstanbul Bilim Üniversitesi Sağlık Yüksekokulu Beslenme ve Diyetetik Bölümü

${ }^{3}$ İstanbul Bilim Üniversitesi Tıp Fakültesi Aile Hekimliği Anabilim Dalı

*Address for Correspondence / Yazışma Adresi: Can Öner, Dr.Lütfi Kırdar Eğitim ve Araştırma Hastanesi Aile Hekimliği Kliniği ,İstanbulTÜRKIYE, E-mail: trcanoner@yahoo.com

Öner C, Özdemir M, Telatar B, Yeșildağ S..Yemek Servisinde Kullanılan Tabakların Boyutu Porsiyon Algısını Etkiliyor mu?. TJFMPC, 2016;10(4): 182187.

DOI: 10.21763/tjfmpc.270704 


\section{GiRiş}

Obezite, biyolojik, davranışsal ve çevresel faktörlerin etkileşimi ile ortaya çıkan önemli bir halk sağlığı sorunudur. Yapılan güncel çalışmalar, obezitenin bu kadar çarpıcı bir biçimde yayılmasını, biyolojik nedenlerden çok çevresel faktörlere bağlamaktadır. ${ }^{1} \mathrm{Bu}$ çevresel faktörler arasında, yüksek enerji ve yağ içeriği olan gıdaların tüketilmesi, fast-food gida tüketimindeki artış, ekran karşısında geçirilen sürenin artması ve porsiyonların büyümesi sayılabilir. Dışarıda yemek yeme alışkanlığı, obezite üzerine etki eden çevresel faktörlerden birisidir. ${ }^{2}$ Dışarıda yemek yemenin yaygınlaşması ile beraber, tüketilen porsiyon boyutlarında son 10-20 yıl içinde belirgin bir artış meydana gelmiştir. ${ }^{3}$

Özellikle son 30 yıl içinde olmak üzere, gıdaların porsiyon büyüklükleri 1970 yılı ile 2000 yılı arasında yaklaşı olarak 10 kat artış göstermiştir. Porsiyonların büyümesine paralel olarak, servis amaçlı kullanılan tabak boyutları da, 1960'dan beri \%36 oranında artış göstermiştir. Servis amaçlı kullanılan tabakların, 1920 yılındaki ilk dizaynları ile şu an kullanılanları arasında servis boyutu \%62 oranında artmıştır. ${ }^{4}$

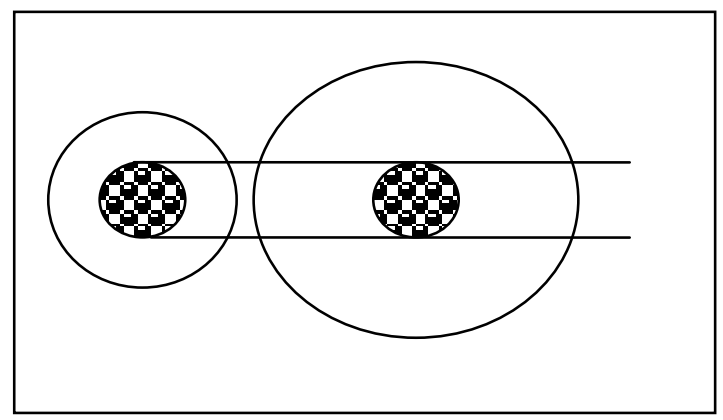

Şekil 1. Delboeuf yanılsaması (1865): Aynı çaptaki iki çemberin çevresinin daha büyük bir çemberle çevrelenmesi durumunda, çevrelenen çemberin daha küçük olarak algılanması

Bireylerin tüketim davranışları küçük çevresel etkilerle değişebilmektedir. Yemek yeme açısından bakıldığında bu etkilerden önemli bir tanesi de tabak boyutudur. Yapılan çalışmalar büyük tabaklar içinde insanların çok daha fazla besin tükettiğini göstermiştir. ${ }^{5}$ Tabak boyutlarının porsiyon algısına etkisi Delboeuf yanılsaması olarak bilinmektedir. Delboeuf, aynı çaptaki iki çemberden birinin çevresinin daha büyük bir çemberle çevrelenmesi durumunda, çevrelenen çemberin daha küçük olarak algılandığını göstermiştir (Şekil 1). ${ }^{6}$ Delboeuf yanılsaması sırasında kullanılan çemberlerin arasındaki boşluk ne kadar küçülürse, kişiler çemberleri bir bütün gibi algıladığı için yanılsama olamazken, çemberler arasındaki mesafe arttıkça yanılsama artmaktadır. Çemberlerin çapları 3:4 oranına ulaştıktan sonra ayrışma ve yanılsama başlamakta ve 1:4 oranına ulaştığında azami düzeyine ulaşmaktadır. $\mathrm{Bu}$ yanılsamanın, gıda sunumu açısından etkisi aynı porsiyon büyüklüğündeki bir yemeğin, küçük tabakla servis edildiğinde olduğundan daha fazla, buna karşın büyük bir tabakla servis edildiğinde ise olduğundan daha az algılanmasıdır. Bu çalışmanın amac1, yiyecek porsiyonlarının görsel tahmini üzerine tabak boyutunun etkisini incelemektir.

\section{YÖNTEM}

Deneysel tipteki bu çalışma, İstanbul Bilim Üniversitesi Sağlık Yüksek Okulu yemekhanesinde çalışmaya katılmayı kabul eden ve yaş aralıkları 2034 arasında değişen 100 öğrenci ile yürütülmüştür. Çalışma için örneklem hesabı yapılmamış, verilerin toplanmaya başlandığı Ocak 2015 sonrasında dahil edilme kriterlerini karşılayan ve çalışmaya katılmak için onam veren öğrencilerle çalışma yürütülmüştür. Çalışma, Nisan 2015'de sonlandırılmış ve bu dönem içinde toplam 100 öğrenciye ulaşılmıştır. Diyet yapan, iştah durumunu etkileyen ilaç kullanım öyküsü, gebelik veya emzirme öyküsü olan öğrenciler çalışma dış1 tutulmuşlardır. Katılımcılardan test öncesi (30 dakika ve daha fazla) su dahil sıvı ve herhangi bir gıda alanlar çalışmaya dahil edilmemiştir. Açlık ve tokluk düzeyleri, porsiyon algısını etkileyebileceği için çalışma tok oldukları saatlerde (15:00-16:00) yürütülmüştür.

Tokluk düzeyi subjektif bir ölçüt olduğundan, kişilerden tokluk durumlarını vizüel analog skala üzerinde işaretlemeleri istenmiştir. $\mathrm{Bu}$ skala, $10 \mathrm{~cm}$ uzunluğunda bir ucunda "tıka basa tokum", diğer ucunda "çok açım" olan bir çizgi idi. Kişilerin işaretlediği noktalar cetvelle ölçülerek 7,5 cm ve üstü değerler " tok " olarak kabul edilmiş, bu değer altı olanlar çalışma dişı tutulmuşlardır. Çalışmada 3 farklı tabak kullanılmıştır.

Kullanılan tabaklar şekil 2'de gösterilmiştir. Bir numaralı tabak $15 \mathrm{~cm}, 2$ numaralı tabak ise $30 \mathrm{~cm}$ çapta düz servis tabaklarıdır. Üç numaralı tabak ise $15 \mathrm{~cm}$ çaplı çukur servis tabağıdır. Renk ve desen Delboeuf yanılsamasına etki edebileceğinden, her üç tabakta da desen veya renk bulunmamaktadır. Pişirilen 1 porsiyon makarna (pişmiş ağırlığı 200 gr), üç ayrı tabakta katılımcılara sunulmuştur. Tabakların eş zamanlı olarak servis edilmesi katılımciların porsiyon tahminlerini etkileyebileceğinden, tabaklar katılımcılara ayrı ayrı servis edilmişlerdir. Servis sunumları her katılımcı için farklı sıra ile yapılmıştır. Servis sunumu 1.,2.,3. tabak olarak başlamış ve sonrasında 2.,3.,1. ve 3.,1.,2. tabak ve tekrarı olacak biçimde ilerlemiștir. Her bir katılımcıdan görsel açıdan tabaklardaki makarnanın porsiyonunun tahmin etmeleri istenmiştir (yarım, bir porsiyon, 1,5 porsiyon vs). Çalışma için etik kurul izni alınmıştır (2015/18 sayılı karar). 


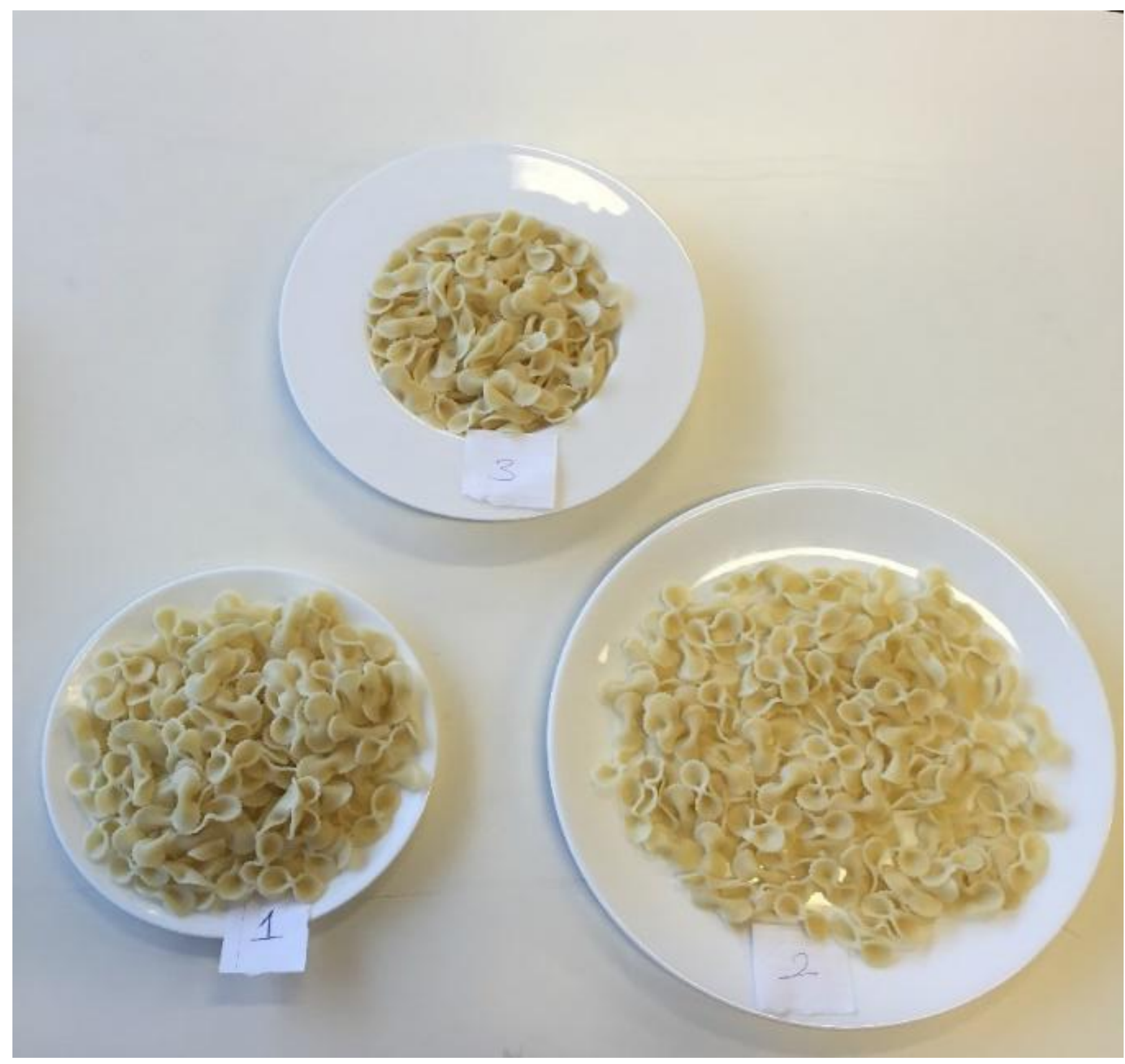

\section{Sekil 2. Serviste kullanılan tabaklar}

Elde edilen veriler, SPSS 17.0 programı kullanılarak analiz edilmiştir. Analizlerde tanımlayıcı ölçütlerden frekans, yüzde; merkezi yığılım ölçütlerinden ortalama ve ortanca; merkezi yaygınlı ölçütlerinden standart sapma ve en büyük-en küçük değer kullanılmıştır. Ayrıca sayımla belirlenen verilerin karşılaştırılmasında kikare analizi kullanılmıştır. P değerleri, 0,05 altında olan değeler anlamlı olarak kabul edilmiştir.

\section{BULGULAR}

Çalışmaya toplam 100 kişi katılmıştır. Katılımciların \%46's1 erkek (s=46) ve \%54'ü ( $\mathrm{s}=54)$ kadındır, yaş ortalaması $25,8 \pm 4,4$ yıldır. Katılımciların ortalama beden kitle indeksi (BKI) $22,5 \pm 3,1 \mathrm{~kg} / \mathrm{m}^{2}$ dir. BKI değerlerine göre sınıflandırıldığında \%6'sı zayıf, \% 74'ü normal, \%17'si kilolu ve \%3'ü obezdir.
Çalışmada kullanılan birinci tabak için beklenen Delboeuf yanılsaması, tabaktaki makarnanın olduğundan daha fazla olarak algılanmasıydı. Birinci tabak için, katılımcıların yarısı bu yanılsamayı yaşamıştır $(\% 49, \mathrm{n}=49)$. İkinci tabak için ise, beklenen yanılsama tabaktaki makarnanın olduğundan daha az olarak algılanmasıydı. Katılımcıların çok az bir kısmı bu yanılsamayı yaşarken $(\% 7, n=7)$, büyük bir kısmı bu tabakta servis edilen makarnanın daha fazla olduğunu bildirmişlerdir $(\% 45, n=45)$. Üçüncü tabakta ise servis edilen makarnanın derinlikten dolayı daha az olarak algılanması beklenmekteydi. Katılımcıların \%23 $(\mathrm{n}=23)^{\prime}$ 'ü bu yanılsamayı yaşarken, \%35'i $(n=35)$ servis edilen makarnanın bir porsiyondan fazla olduğunu belirtmiştir. Katılımcıların, her bir tabak için tabaklardaki makarna miktarı ile ilgili tahminleri tablo 1,2 ve 3 'te verilmiştir. 


\begin{tabular}{|c|c|c|c|}
\hline \multicolumn{4}{|c|}{$\begin{array}{l}\text { Tablo 1. Bir (1) numaralı küçük düz tabak } \\
\text { için yapılan tahminler }\end{array}$} \\
\hline & $\begin{array}{c}<1 \\
\text { porsiyon } \\
\text { tahmin } \\
\text { edenler } \\
(\%)\end{array}$ & $\begin{array}{c}1 \\
\text { porsiyon } \\
\text { tahmin } \\
\text { edenler } \\
(\%)\end{array}$ & $\begin{array}{c}>1 \\
\text { porsiyon } \\
\text { tahmin } \\
\text { edenler } \\
(\%)\end{array}$ \\
\hline Toplam & 9 & 42 & 49 \\
\hline Kadın & 5 & 20 & 29 \\
\hline Erkek & 4 & 22 & 20 \\
\hline $\begin{array}{l}\text { BKI }<25 \\
\mathrm{~kg} / \mathrm{m}^{2}\end{array}$ & 7 & 33 & 40 \\
\hline $\begin{array}{l}\mathrm{BKI} \\
25 \mathrm{~kg} / \mathrm{m} 2\end{array}$ & 2 & 9 & 9 \\
\hline \multicolumn{4}{|c|}{$\begin{array}{l}\text { * Delboeuf yanılsaması yaşayanlar koyu renkte } \\
\text { gösterilmiştir. }\end{array}$} \\
\hline
\end{tabular}

\begin{tabular}{|l|l|c|c|}
\hline \multicolumn{4}{|l|}{ Tablo 2. İki (2) numaralı (büyük düz) tabak için } \\
yapılan tahminler \\
\hline $\begin{array}{c}<1 \\
\text { porsiyon } \\
\text { tahmin } \\
\text { edenler } \\
(\%)\end{array}$ & $\begin{array}{c}1 \text { porsiyon } \\
\text { tahmin } \\
\text { edenler } \\
(\%)\end{array}$ & $\begin{array}{c}>1 \\
\text { porsiyon } \\
\text { tahmin } \\
\text { edenler } \\
(\%)\end{array}$ \\
\hline Toplam & 7 & 48 & 45 \\
\hline Kadın & 4 & 26 & 24 \\
\hline Erkek & 3 & 22 & 21 \\
\hline $\begin{array}{l}\text { BKI < 25 } \\
\text { kg/m }{ }^{2}\end{array}$ & 6 & 37 & 37 \\
\hline $\begin{array}{l}\text { BKI } \\
25 \mathrm{~kg} / \mathrm{m} 2\end{array}$ & 1 & 11 & 8 \\
\hline $\begin{array}{l}* \text { Delboeuf yan1lsamas1 } \\
\text { gösterilmiştir. }\end{array}$ & yaşayanlar koyu renkte \\
\hline
\end{tabular}

\begin{tabular}{|l|l|c|c|}
\hline \multicolumn{4}{|l|}{ Tablo 3. Üç (3) numaralı (orta boy çukur ) } \\
tabak için yapılan tahminler
\end{tabular}

Servis edilen makarnanın, porsiyonunu doğru tahmin etme açısından kadınlar ve erkekler arasında her üç tabak içinde anlamlı bir farklılık bulunamamıştır ( 1 numaralı tabak için $\chi=1,187$; $\mathrm{p}=0,276 ; 2$ numaralı tabak için $\chi=0,001 ; \mathrm{p}=0,974$ ve 3 numaralı tabak için $\chi=1,187 ; \mathrm{p}=0,276$ ). Katılımcıların BKI $25 \mathrm{~kg} / \mathrm{m}^{2}$ ve üstü kesme değeri olarak alındığında kilolu ve obez olan grupla, normal ve zayif olan grup arasinda porsiyon büyüklüğünün doğru tahmin edilmesi açısından üç tabak için anlamlı bir farklılık saptanmamıştır (1 numaralı tabak için $\chi=0,092 ; \mathrm{p}=0,761 ; 2$ numaralı tabak için $\chi=0,092 ; \mathrm{p}=0,761$ ve 3 numaralı tabak için $\chi=0,491 ; \mathrm{p}=0,483$ ).

\section{TARTIŞMA}

Tabak boyutlarının, yiyecek miktarı alg1S1 üzerindeki etkisinin bir k1smı Delboeuf yanılsamasıyla ilgilidir. Delboeuf yanılsaması, iki eş merkezli çemberin göreceli boyutu, iç çemberin çap1 (yiyecek porsiyonu) ve dış çemberin çap1 (kabın, tabağın sınırı) arasındaki ilişkiye dayanır. ${ }^{7}$ İki çember arasındaki renk kontrastının artması durumunda, eş merkezli çemberlerin arasındaki farklılık daha belirgin hale gelmektedir. D1ş çemberin sınırının vurgulanması amacıyla, tabak çevresine farklı renkte bir çevre deseni veya rengi geçirilmesi ve iç çember ve dış çember arasında renk kontrastı oluşturulması, iç merkezdeki çemberin olduğundan daha küçük görülmesini sağlayabilir. ${ }^{8}$ Gıda sunumu açısından bakıldığında, servis tabağının dış çevresinin desen veya renkle belirgin hale getirilmesi, sunumu yapılan gidanın tabakla renk kontrastı yapması, sunulan gida ile tabak dış sınırı arasında çap oranının 1:4 ulaşması azami düzeyde yanılsama yaşanmasını beraberinde getirmektedir.

$\mathrm{Bu}$ çalışmada, desen ve renk kontrastın değişkenleri azami düzeyde tutularak, yalın Delboeuf yanılsamasının etkisi incelenmeye çalışılmıştır. Delboeuf yanılsaması gereği, katılımcıların 1 numaralı tabaktaki makarnayı olduğundan fazla, 2 numaralı ve 3 numaralı tabakta servis edilen makarnayı olduğundan az olarak algılamaları beklenmekteydi. Beklenen yanılsamalardan en çok yanılsama 1 numaralı tabakta yaşanırken (\%49), 2 numaralı tabakta yanılsama yaşayanların oranı $\% 7$ ve 3 numaralı tabakta yanılsama yaşayanların oranı \%23 olarak bulunmuştur. Şaşırtıcı bir biçimde 2 numaralı tabakta servis edilen makarnay1, katılımcıların yaklaşık yarısı (\%45) olduğundan fazla olarak algılamışlardır.

Porsiyon algısına, tabak boyutlarının etkisi olup olmadığ halen net olarak aydınlatılamamıştır. Literatürde bireylerin porsiyon algıları ve besin tüketimlerinin servis için kullanılan tabakların boyutuyla ilişkili olduğunu gösteren çalışmalar olduğu kadar, tabak boyutunun porsiyon algis1 üzerine etki etmediğini bildiren çalışmalarda mevcuttur.

Wansink ve Cheney tarafindan 2005 yılında yapılan bir çalışmada, gıda olarak cips ve çerez, serviste ise $2000 \mathrm{ml}$ ve $4000 \mathrm{ml}$ alan kâseler kullanılmış, büyük ve küçük kâseler arasında 
porsiyon algısı açısından anlamlı bir farklılık bulunmuştur. $^{5}$ İki yüz yetmiş öğrenci ile yürütülen bir başka çalışmada ise çapları 23 ve $28 \mathrm{~cm}$ olan kâğıt tabaklar kullanılmıştır. Çalışmada, katılımcıların akşam yemeğinde sevdikleri bir gıda servis edilmiş, büyük ve küçük tabak arasında porsiyon algısı bakımından anlamlı bir farklılık gösterilmiştir. Ancak bu çalışmada, gıda türünün standardize edilememiş olması önemli bir kısıtlılıktır. ${ }^{9}$ Tabak boyutunun porsiyon algısına etkisi olduğunu gösteren, çocuklar üzerinde yürütülen bir başka çalışmada et kullanılmış, servis ise çapları 18.4 ve $26 \mathrm{~cm}$ olan porselen tabaklarla yapılmıştır. ${ }^{10}$ Öte yandan Rolls ve arkadaşları 44 erişkini kapsayan ve sunumunda et ve 17, 22, 26 $\mathrm{cm}$ çapındaki porselen tabakları kullandıkları çalışmada, tabak boyutlarının porsiyon algısını etkilemedikleri sonucuna varmışlardır. ${ }^{11}$ Yine, Yip ve arkadaşları da kilolu ve obez kadın katılımcılardan oluşan çalışma gruplarına, 19,5 cm ve $26,5 \mathrm{~cm}$ çapli porselen tabaklarda sunum yapmışlar ve tabak boyutlarının porsiyon algısını etkilemediği sonucuna varmışlardır. ${ }^{12}$

Yapılan çalışmalarda kullanılan gıda ürünlerinin ve tabak şekil ve boyutlarının değişik olması, bazı çalışmalarda ise çevresel faktörlerin eklenmesi gibi nedenlerle kıyas yapılması zorlaşmaktadır. Literatürde çalışmamıza benzer çalışmalarda mevcuttur. Rolls ve arkadaşları tarafından 2007 yılında yapılan bir çalışmada, sirasıyla 17,22 ve $26 \mathrm{~cm}$ çaplı düz beyaz porselen tabaklara, 45 erişkine self servis olarak ve otuz erişkine de 22 ve $30 \mathrm{~cm}$ çaptaki düz beyaz porselen tabaklarda, servise hazır olarak peynirli makarna servisi yapılmış ve tabak boyutlarının porsiyon algısını etkilemediği sonucuna varılmıştır. ${ }^{11}$ Yine domates soslu makarnanın kullanıldığı bir başka çalışmada, 48 öğrenci çalışmaya alınmış ve öğrencilere $200 \mathrm{~g}$ pişmiş makarna $9 \mathrm{~cm}$ ve $24 \mathrm{~cm}$ çaptaki tabaklarda servis edilmiştir. Çalışma sonucunda tabak boyutlarının porsiyon algısını etkilemediği sonucuna varılmıştır. ${ }^{7}$

Delboeuf yanılsaması test dairesi ile, bu daireyi çevreleyen daire arasında kalan boşluk miktarına dayanmaktadır. Diğer bir deyişle daireler arasındaki boşluğun küçük olması görüntünün bütüncül olarak algılanmasına yol açmaktadır. ${ }^{6}$ Makarna besin öğesi olarak böyle bir test dairesi (iç daire) oluşturamamaktadır. Bizim çalışmamızda makarna kullanılmıştır. Makarna sunumu açısından tabak içinde kesin sınırlı bir alan yaratamamaktadır (Şekil 1). Bu durumun yanılsama oranlarını azalttığını düşünüyoruz. Çapları aynı olmasına karşın, 3. tabakta daha fazla kişinin beklenen yanılsamayı yaşaması (\%23) üçüncü tabağın çukur tabak olması nedeni ile daha keskin bir test dairesi (iç daire) oluşturması nedeniyle olduğunu düşünüyoruz. Benzer şekilde $3800 \mathrm{~mL}$ ve $6900 \mathrm{~mL}$ hacme sahip iki farklı kâsenin kullanıldığı ve domates soslu makarna servisi yapılan bir başka çalışmada kap boyutunun porsiyon algısını etkilediği soncuna varılmıştır. ${ }^{13}$ McClain ve arkadaşlarının yaptıkları ve 338 kişinin katıldığı bir çalışmada, tabak boyutunun porsiyon algısına etkisi incelenmiş büyük tabakla servis edilen gıdaların, olduğundan daha az algılandığını göstermiştir. Aynı çalışmada, tabak kenarında çerçeve geçirilmesinin de benzer şekilde algılanan porsiyon üzerinde etkisi olduğu gösterilmiştir. ${ }^{8}$

Öte yandan 2 numaralı tabakta servis edilen makarnanın, beklenilenin aksine bir porsiyondan daha fazla olduğunu bildiren katılımcıların oranının \%45 olması, kapların boyutunun da sinıflandırmayı yönlendirebildiğini düşündürmektedir. Yapılan bir çalışmada, katılımcıların \%47,9'u büyük düz tabaklarla servis edilen makarnayı daha fazla bulurken, bu oran küçük düz tabak için \%22,9 olarak bulunmuştur. ${ }^{7}$

Katılımcıların doğru porsiyon tahmini, beden kitle indeksleri açısından karşılaştırıldığında tabaklar arasında anlamlı bir farklılık saptanmadı. Literatürde, bizim çalışmamıza benzer sonuçlar olduğu kadar ${ }^{14}$, BKI ile porsiyon tahmini arasında ilişki olduğunu gösteren çalışmalar da mevcuttur. ${ }^{15}$

Çalışmanın önemli kısıtlılıklarından birisi, çalışmada kullanılan gıdanın Delboeuf yanılsamasını gerçekleştirebilecek ölçüde iç daire sınırı oluşturamamasıdır. Çalışma katılımcıların hepsinin benzer yaş grubu ve benzer beslenme örüntüleri olması nedeni ile çalıșma sonuçlarının genellemesinde dikkatli olunmalıdır. Gıda tabak arasındaki renk kontrastı ilişkisi ( makarna açısından bakıldığında) çok zayıf olması, yine yanılsama üzerine negatif olarak etki etmiş olabilir.

\section{SONUÇ}

Sonuç olarak, küçük düz servis tabağı kullanılarak servis edilen makarna ile katılımcıların \%49'u Delboeuf yanılsaması yaşamış ve servis edilen makarnayı daha fazla olarak algılanmıştır. Delboeuf yanılsamasının renk, kontrast ve çevresel faktörler ile olan ilişkisinin daha net ortaya çıkarılması obezite ile mücadelede önemli bir katk1 sağlayabilir. Çalışmamız özelinde, katılımcıların yaklaşık yarısının küçük tabakta sunulan makarna ile yanılsama yaşamış olması, yemeklerin daha küçük düz kaplarla servis edilmesi algılanan porsiyon miktarını değiştirerek, kişilerin enerji alımlarını azaltabileceği ve obeziteyle mücadele açısından maliyet etkin bir yöntem olarak kullanılabileceğini düşündürmektedir. 


\section{KAYNAKLAR}

1. Brantley PJ, Myers VH, Roy HJ. Enviromental and life style influences on obesity. J La State Med Soc 2005;157 (1):19-27.

2. Ledikwe JH, Ello-Martin JA, Rolls BJ. Portion size and the obesity epidemic. J Nutr 2005;135(4):905-909.

3. Akarçay E, Suğur N. Dışarıda yemek: Eskişehir'de yeni orta sınıfin fast-food yemeiçme örüntüleri. JSR 2015; 18 (1):1-29.

4. Nielsen SJ, Popkin BM. Patterns and trends in food portion sizes, 1977-1998. JAMA 2003;289 (4):450-453.

5. Wansink B, Cheney MW. Super Bowls: Serving bowl size and food consumption. JAMA 2005; 293(14):1732-1728. DOI:10.1001/jama.293.14.1727.

6. Ittersum KV, Wansink B. Plate size and color suggestibility: Delboeuf Illusion's bias on serving and eating behavior. J Consum Res 2012; 39(2):215-228.

7. Penaforte FRO, Japur CC, Diez-Garcia RW, Hernandez JC, Palmma-Linares I, Chiarello PG. Plate size does not affect perception of food portion size. J Hum Nutr Diet 2014; 27(S2):214-219. DOI:10.1111/jhn.12111nsink

8. McClain $\mathrm{AD}$, van der Bos $\mathrm{W}$, Matheson $\mathrm{D}$, Desai M, McClure SM, Robinson TN. Visual illusions and plate design: the effects of plate rim widths and rim coloring on perceived food portion size. Int J Obes (Lond) 2014;38(5): 657-662. DOI: 10.1038/ijo.2013.169.

9. Sharp D, Sobal J.Using plate mapping to examine sensitivity to plate size in food portions and meal composition among college students. Appetite 2012;59(3): 639-645

10. DiSantis KI, Birch LL, Davey A, Serrano EL, Zhang J, Bruton Y, et al.Plate size and children's appetite. Effects of larger dishware on self-served portions and intake. Pediatrics 2013;131(5): 1451-1458.

11. Rolls BJ, Roe LS, Halverson KH, Meengs JS. Using a smaller plate did not reduce energy intake at meals. Appetite 2007;49 (3):652-660.

12. YipW, Wiessing KR, Budgett S, Poppitt SD. Using a smaller dining plate does not suppress food intake from a buffet lunch meal in overweight, unrestrained women. Appetite $2013 ; 69: 102-7$.

13. van Kleef E, Shimizu M, Wansink B.Serving bowl selection biases the amount of food served. J Nutr Educ Behav 2012;44(1):66-70.

14. Brunstrom JM, Rogers PJ, Pothos EM, Calitri R, Tapper K. Estimating everyday portion size using a 'method of constant stimuli': in a student sample, portion size is predicted by gender, dietary behaviour, and hunger, but not BMI. Appetite 2008; 51(2):296-301

15. Burger KS, Kern M, Coleman KJ. Characteristics of self-selected portion size in young adults. J Am Diet Assc 2007; 107:611818. 